\title{
Label Free Glucose Electrochemical Biosensor Based on Poly(3,4-ethylenedioxy thiophene):Polystyrene Sulfonate/Titanium Carbide/Graphene Quantum Dots
}

\author{
Siti Nur AshakirinMohd Nashruddin 1 ${ }^{\mathbb{D}}$, Jaafar Abdullah ${ }^{2}{ }^{(0}$, Muhammad Aniq Shazni Mohammad Haniff ${ }^{1}$, \\ Mohd Hazani Mat Zaid ${ }^{1, * \mathbb{D}}$, Ooi Poh Choon ${ }^{1}$ and Mohd Farhanulhakim Mohd Razip Wee ${ }^{1, *(D)}$ \\ 1 Institute of Microengineering and Nanoelectronics (IMEN), Universiti Kebangsaan Malaysia (UKM), \\ Bangi 43600, Selangor, Malaysia; p103435@siswa.ukm.edu.my (S.N.A.N.); \\ aniqshazni@ukm.edu.my (M.A.S.M.H.); pcooi@ukm.edu.my (O.P.C.) \\ 2 Department of Chemistry, Faculty of Science, University Putra Malaysia, Serdang 43400, Selangor, Malaysia; \\ jafar@upm.edu.my \\ * Correspondence: zani.ukm@gmail.com (M.H.M.Z.); m.farhanulhakim@ukm.edu.my (M.F.M.R.W.); \\ Tel.: +60-38911-8159 (M.F.M.R.W.)
}

check for updates

Citation: Nashruddin, S.N.A.; Abdullah, J.; Mohammad Haniff, M.A.S.; Mat Zaid, M.H.; Choon, O.P.; Mohd Razip Wee, M.F. Label Free Glucose Electrochemical Biosensor Based on Poly(3,4-ethylenedioxy thiophene):Polystyrene Sulfonate/Titanium Carbide/Graphene Quantum Dots. Biosensors 2021, 11, 267. https://doi.org/10.3390/ bios11080267

Received: 28 April 2021

Accepted: 23 June 2021

Published: 7 August 2021

Publisher's Note: MDPI stays neutral with regard to jurisdictional claims in published maps and institutional affiliations.

Copyright: (c) 2021 by the authors. Licensee MDPI, Basel, Switzerland. This article is an open access article distributed under the terms and conditions of the Creative Commons Attribution (CC BY) license (https:/ / creativecommons.org/licenses/by/ $4.0 /)$.

\begin{abstract}
The electrochemical biosensor devices based on enzymes for monitoring biochemical substances are still considered attractive. We investigated the immobilization of glucose oxidase (GOx) on a new composite nanomaterial poly(3,4-ethylenedioxythiophene): polystyrene sulfonate (PEDOT:PSS)/titanium carbide, $\left(\mathrm{Ti}_{3} \mathrm{C}_{2}\right)$ /graphene quantum dots(GQD) modified screen-printed carbon electrode (SPCE) for glucose sensing. The characterization and electrochemical behavior of PEDOT:PSS $/ \mathrm{Ti}_{3} \mathrm{C}_{2}$ /GQD towards the electrocatalytic oxidation of GOx was analyzed by FTIR, XPS, SEM, cyclic voltammetry (CV), and differential pulse voltammetry (DPV). This composite nanomaterial was found to tend to increase the electrochemical behavior and led to a higher peak current of $100.17 \mu \mathrm{A}$ compared to $82.01 \mu \mathrm{A}$ and $95.04 \mu \mathrm{A}$ for PEDOT:PSS and PEDOT:PSS $/ \mathrm{Ti}_{3} \mathrm{C}_{2}$ alone. Moreover, the detection results demonstrated that the fabricated biosensor had a linear voltammetry response in the glucose concentration range $0-500 \mu \mathrm{M}$ with a relatively sensitivity of $21.64 \mu \mathrm{AmM}^{-1} \mathrm{~cm}^{-2}$ and a detection limit of $65 \mu \mathrm{M}(\mathrm{S} / \mathrm{N}=3)$, with good stability and selectivity. This finding could be useful as applicable guidance for the modification screen printed carbon (SPCE) electrodes focused on composite PEDOT:PSS/ $\mathrm{Ti}_{3} \mathrm{C}_{2} / \mathrm{GQD}$ for efficient detection using an enzyme-based biosensor.
\end{abstract}

Keywords: screen printed carbon electrode; nanocomposite; biosensor; glucose oxidase; electrochemical biosensor; polystyrene sulfonate (PEDOT:PSS); titanium carbide $\left(\mathrm{Ti}_{3} \mathrm{C}_{2}\right)$; graphene quantum dots (GQD); redox mediator free

\section{Introduction}

Diabetes disease is a condition with an excess of blood glucose that mainly originates from unhealthy food consumption [1]. Thus, without continuous careful management, it can lead to the build-up of sugar in the blood, which can raise the risk of harmful complications, including strokes and heart disease. According to the World Health Organization (WHO) report, diabetes was the seventh leading cause of death in 2016. Experts also claim that diabetes can be reversed as early as 3-5 years in disease by normalizing blood sugar levels without medication. Therefore, early identification of glucose in the blood would prevent diabetes [2], presenting a need to establish simple diagnoses for potential patients with diabetes.

The electrochemical biosensor has become an attractive choice for high throughput analysis with increased sensitivity, rapidity, and selectivity of data collection by using a small volume of the sample [3]. Moreover, in advance of technology, the screen-printed electrode seems widely used in the electrochemical research field due to its simplicity, low 
cost, simple fabrication, fast response, disposable, portable, and can be used as a point of care (POC) device [4]. Nevertheless, the limitations of screen-printed carbon electrodes (SPCE) are mostly related to low current if used without any modifications which restrict its selectivity and sensitivity. To increase the efficiency of SPCE, the working electrode surface normally needs to be modified by adding a modifier that provides higher conductivity and accelerates the transfer of electrons [5]. Such electrode modifications may strengthen signal transduction at the electrode-electrolyte interchange by improving sensitivity and limits of detection [6].

The advent of conductive polymers such as PEDOT:PSS, poly(3,4-ethylenedioxythiophene) polystyrene sulfonate has been used to enhance the conductivity of electrodes with moderate band gap, good stability, and low redox potential [7]. It can be easily deposited as thin films by various methods such as spin-coating, dip-coating, or inkjet micro deposition [8]. In addition, it is highly employed in enzyme-based biosensors due to its high enzyme immobilization ability [9]. However, the poor electrocatalytic capability of PEDOT:PSS limited its electrochemical application in sensors [10]. Few studies have demonstrated the incorporation of graphene-based material or metallic nanoparticles into PEDOT:PSS to form a nanocomposite that stabilizes the electron transport and improves its flexibility and conductivity $[11,12]$

Titanium carbide, $\mathrm{Ti}_{3} \mathrm{C}_{2}$, also called MXene, an evolving family of (2D) materials inorganic materials, holds great promise as the ideal candidate sensing platform to produce electrochemical biosensors have shown outstanding electronic properties [13]. MXene based composite materials have received particular attention due to the synergistic effect, low interfacial resistance, and electrical conductivities [14]. Previously, a PEDOT:PSS $/ \mathrm{Ti}_{3} \mathrm{C}_{2}$ hybrid composite demonstrated improved electrochemical sensing capabilities and showed excellent conductivity compared to the simple PEDOT:PSS modified electrodes [15].

Among graphene families, graphene quantum dots demonstrate high improvement due to quantum confinement and edge effects, giving rise to the unique electronic, optoelectronic, photoelectric, enlarged surface to mass ratio, and high conductivity properties [16]. Graphene quantum dot (GQD) has zero-dimensional (0D) nanostructure derived from the carbon family with properties derived from both graphene and carbon dots (CDs) [17]. GQD is a non-toxic and bio-inert material that is considered environmentally friendly $[18,19]$. In addition, GQD also can be dispersed in water easily due to its functional groups providing hydrophilicity conditions [20]. The electrochemical behavior and electrical conductivity of composite materials such as PEDOT:PSS/ $\mathrm{Ti}_{3} \mathrm{C}_{2}$ can be improved by GQD modification [21]. The PEDOT:PSS $/ \mathrm{Ti}_{3} \mathrm{C}_{2} /$ GQD nanocomposite modified electrodes were used without a binder to increase the electrochemical reaction rate, reduce adsorption, and shorten the ion diffusion path.

In this nanocomposite, PEDOT:PSS will act as an effective electrical conductor as well as a polymeric binder to produce a stable dispersion of GQD and $\mathrm{Ti}_{3} \mathrm{C}_{2}$, which are important in improving electrocatalytic activity towards glucose detection [22]. Therefore, we proposed PEDOT:PSS $/ \mathrm{Ti}_{3} \mathrm{C}_{2} / \mathrm{GQD}$ for electrode modification. The variable concentration of glucose as an analyte of study was analyzed using the differential pulse voltammetry (DPV) technique. Moreover, the stability, repeatability, and interference effects of the proposed biosensor have also been investigated. Using facile methods with the involvement of any cross-linker, it was found that the proposed biosensor was sensitive enough for the detection of glucose with excellent selectivity and stability.

\section{Materials and Methods}

\subsection{Chemical and Reagents}

Glucose, glucose oxidase (GOx), and poly(3,4-ethylenedioxythiophene)-polystyrenesulfonate (PEDOT:PSS, 666201) were purchased from Sigma-Aldrich, St. Louis, MO, USA. Graphene quantum dot (GNQD0101) was purchased from ACS Materials and titanium carbide, $\mathrm{Ti}_{3} \mathrm{C}_{2}$ was derived from the typical exfoliation of MAX phase $\left(\mathrm{Ti}_{3} \mathrm{AlC}_{2}\right)$ method [23]. Acetic acid and ammonia were purchased from Sigma-Aldrich were mixed to obtain a 
solution of $0.1 \mathrm{M}$ ammonium acetate solution, $\mathrm{pH}$ 7. Potassium ferricyanide $\mathrm{K}_{3} \mathrm{Fe}(\mathrm{CN})_{6}$, was purchased from R\&M Chemicals, Malaysia. Deionized (DI) water was used throughout the experiments.

\subsection{Instrumentation}

Cyclic voltammetry and DPV were performed using mini PSTAT 910 (Metrohm Ltd. Herisau, Switzerland) controlled by the personal computer. A screen-printed carbon electrode (SPCE, DRP C110) with a diameter of $4 \mathrm{~mm}$ was purchased from Dropsens (Oviedo, Spain). The electrode consists of the working electrode (carbon), reference electrode $(\mathrm{Ag} / \mathrm{Cl})$, and counter/auxiliary electrode (carbon), respectively.

\subsection{Preparation of PEDOT:PSS $/ \mathrm{Ti}_{3} \mathrm{C}_{2} / G Q D-G O x$ Modified Electrode}

Preparation of PEDOT:PSS $/ \mathrm{Ti}_{3} \mathrm{C}_{2} / \mathrm{GQD}$ of 1:1:1 $(v / v / v)$ ratio was mixed and sonicated at $30^{\circ} \mathrm{C}$ for $10 \mathrm{~min}$. Then, the nanocomposite material was stored overnight $(24 \mathrm{~h})$ at room temperature. Subsequently, $3 \mu \mathrm{L}$ of PEDOT:PSS $/ \mathrm{Ti}_{3} \mathrm{C}_{2} / \mathrm{GQD}$ nanocomposite was uniformly drop-cast onto the electrode surface of the SPCE and left to dry (2 h) at room temperature. Prior to the modification phase, the electrode is activated by $\mathrm{CV}$ for approximately 50 cycles in $\mathrm{KCl}$ at a scan rate of $100 \mathrm{mV} / \mathrm{s}$. Next, $3 \mu \mathrm{L}$ of $0.1 \mathrm{M} \mathrm{GOx}$ was immobilized on the modified SPCE and left for two hours to dry. After the enzymatic layer was formed, the electrode was rinsed with a stream of a phosphate-buffered solution to remove the residual monomer and weakly linked enzyme molecule prior to taking the measurements. A schematic diagram of PEDOT:PSS $/ \mathrm{Ti}_{3} \mathrm{C}_{2} / \mathrm{GQD} / \mathrm{GOx}$ modified SPCE glucose biosensor is illustrated in Figure 1. The detection mechanism of the developed biosensor in this study can be classified as a third-generation glucose biosensor which is capable of direct electron transfer, providing an electrical signal to be measured.

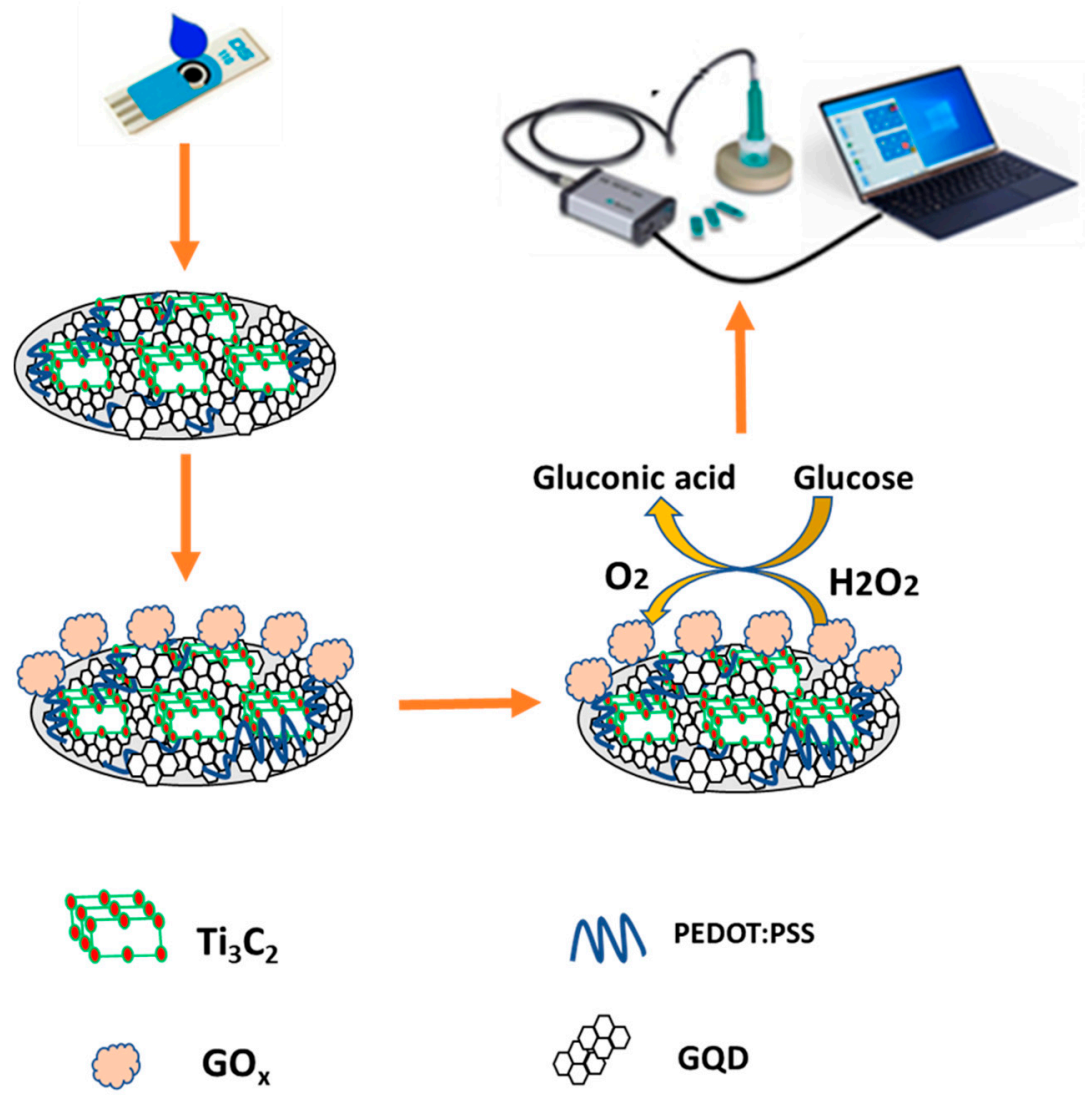

Figure 1. Schematic diagram of fabricated PEDOT:PSS/ $\mathrm{Ti}_{3} \mathrm{C}_{2} / \mathrm{GQD}$ modified SPCE for glucose detection. 


\subsection{Characterization}

A scanning electron microscope (SEM) (JEOL) was used to observe the surface morphologies of nanocomposites on SPCE. A high-resolution transmission electron microscope (HR-TEM) system (JEOL, JEM-2010) operated at an accelerating voltage of $200 \mathrm{kV}$ was used to determine the size and distribution of the nanomaterials. FTIR spectroscopy (FT/IR6100TypeA, JASCO) was carried out to examine the functional group of nanocomposite materials with immobilized glucose oxidase. X-ray photoelectron spectroscopy (XPS) on an Axis Ultra DLD, Kratos/Shimadzu with Al monochromatic source (1486.69 eV) with charge compensation system was utilized to determine the elemental composition and oxidation state of the prepared samples. The obtained results were analyzed by CasaXPS software using the Shirley algorithm and GL (30) line shape.

\subsection{Electrochemical Measurements of PEDOT:PSS/Ti ${ }_{3} \mathrm{C}_{2} / G Q D-G O x$}

The calibration curves were statistically analyzed by OriginPro 8.0 and the relevant results (slope and intercept) were evaluated. All voltammetric measurements were performed in triplicate $(n=3)$ at room temperature. Limit of detection (LOD) was calculated based on three times the standard deviation of the intercept divided by the slope of the calibration curve. The effective surface area of the electrode was determined by the Randles-Sevcik equation:

$$
i_{\mathrm{p}}=\left(2.69 \times 10^{5}\right) \mathrm{n}^{3 / 2} D^{1 / 2} \mathrm{CAv}^{1 / 2}
$$

where the $n$ is the number of transferred electrons for the redox reaction, $D$ is the diffusion coefficient $\left(6.7 \times 10^{-6} \mathrm{~cm}^{2} \mathrm{~s}^{-2}\right), \mathrm{C}$ is the molarity of ferricyanide $0.1 \mathrm{M}, A$ is the effective surface area in $\mathrm{cm}^{2}$, and $v$ is the scan rate $\left(\mathrm{mVs}^{-1}\right)$.

The effective surface area was performed at various scan rates, and with a wellestablished linear relationship between current $(i)$ and square root scan rate $\left(v^{1 / 2}\right)$ by performing linear regression for $i$ versus $v^{1 / 2}$, the slope $k$ was obtained and the effective surface area [24] is expressed as:

$$
A=\frac{k}{\left(2.69 \times 10^{5}\right) n^{3 / 2} D^{1 / 2} \mathrm{C}}
$$

\section{Results}

\subsection{FTIR and XPS Analysis}

The FTIR spectra of PEDOT:PSS $/ \mathrm{Ti}_{3} \mathrm{C}_{2} / \mathrm{GQD}$ were measured in the presence and absence of glucose oxidase immobilization. Figure 2A (spectrum a) indicates the transmittance of the PEDOT:PSS $/ \mathrm{Ti}_{3} \mathrm{C}_{2} / \mathrm{GQD}$ without GOx displays a weak $\mathrm{C} \equiv \mathrm{C}$ band at a peak of $2116 \mathrm{~cm}^{-1}$, while the presence of a peak at $1640 \mathrm{~cm}^{-1}$ is assigned to the $C=C$ group. The absorption peak at $1513 \mathrm{~cm}^{-1}$ shows $\mathrm{C}=\mathrm{O}$ stretching vibration, which suggests the presence of oxygen-containing groups in PEDOT:PSS. Moreover, an exhibition of several fingerprint bands due to the existence of PEDOT:PSS for C-O and C-O-C stretching mode (ethylenedioxy group) at a peak of $1292 \mathrm{~cm}^{-1}$ and $1025 \mathrm{~cm}^{-1}$, respectively. Other bands were formed at a peak of $899 \mathrm{~cm}^{-1}$ and $755 \mathrm{~cm}^{-1}$ due to C-H aromatic bending. Subsequently, spectrum $\mathrm{b}$ containing the predicted bands of PEDOT:PSS and GOx functional groups confirms the active immobilization of the enzyme. The existence of carboxyl-activated PEDOT:PSS can be determined by the broad peaks at $3282 \mathrm{~cm}^{-1}$ and $2950 \mathrm{~cm}^{-1}$ corresponding to the O-H and $\mathrm{C}-\mathrm{H}$ stretch, with the another peak at $1637 \mathrm{~cm}^{-1}$ that represents the $\mathrm{C}=\mathrm{C}$ stretch. In addition, the sulphate group in the PEDOT:PSS backbone contributes to the $\mathrm{C}-\mathrm{O}$ and $\mathrm{S}=\mathrm{O}$ stretching bands at $1187 \mathrm{~cm}^{-1}$ and $1045 \mathrm{~cm}^{-1}$. Furthermore, PEDOT:PSS $/ \mathrm{Ti}_{3} \mathrm{C}_{2} / \mathrm{GQD}$ indicates more pronounced peaks from the GOx group. Thus, GQD can also help boost the immobilization of GOx on SPCE [18]. Moreover, $\mathrm{Ti}_{3} \mathrm{C}_{2}$ induces perturbations of certain peak amplitudes and locations as seen at peaks $598 \mathrm{~cm}^{-1}$ and $627 \mathrm{~cm}^{-1}$ (Ti-O) for modified electrodes immobilized with GOx and without GOx [18]. 
Subsequently, the chemical constitution and the structure of the PEDOT:PSS $/ \mathrm{Ti}_{3} \mathrm{C}_{2} /$ GQD were investigated by X-ray photoelectron spectroscopy (XPS). The general survey of the XPS spectrum of the PEDOT:PSS $/ \mathrm{Ti}_{3} \mathrm{C}_{2} / \mathrm{GQD}$ shows three strong binding energy peaks at 165.4, 284.9 and $530.6 \mathrm{eV}$ were attributed to $\mathrm{S} 2 \mathrm{p}, \mathrm{C} 1 \mathrm{~s}$, and $\mathrm{O} 1 \mathrm{~s}$, respectively (S1). The PEDOT:PSS $/ \mathrm{Ti}_{3} \mathrm{C}_{2} / \mathrm{GQD}$ were composed of S (1.56\%), C (78.81\%), and O (19.63\%), especially, in the high-resolution spectrum of $S 2 p$ (Figure $2 B$ ), where there were two peaks at $160.6(0.09 \%)$ and $161.6(0.49 \%)$ which were attributed to $S 2 \mathrm{p}^{3 / 2}$, and one peak at 165.4 $(1.03 \%) \mathrm{eV}$ which was attributed to $\mathrm{S} 2 \mathrm{p}^{1 / 2}$ species, respectively. Three remarkable peaks in the $\mathrm{C} 1 \mathrm{~s}$ spectrum at $284.9(58.26 \%), 286.5(13.32 \%)$, and $289.0(5.56 \%) \mathrm{eV}$ (Figure $2 \mathrm{C}$ ) were attributed to $\mathrm{C}-\mathrm{C}, \mathrm{C}-\mathrm{O}$, and $\mathrm{C}=\mathrm{O}$ groups. In the $\mathrm{O} 1 \mathrm{~s}$ spectrum (Figure $2 \mathrm{D}$ ), two peaks at $529.2(13.61 \%)$ and $530.6(7.63 \%) \mathrm{eV}$ both were attributed to O-Ti groups, indicating the presence of Ti bonding by MXene [25,26].

Subsequently, Figure 3 shows HRTEM and SEM characterization was carried out to investigate the morphology of nanocomposite thoroughly. As depicted in Figure 3A, the GQD morphology was investigated with a high-resolution transmission electron microscope (HRTEM) display a quasi-spherical, mono-dispersed, and homogeneously distributed with an average diameter of less than $10 \mathrm{~nm}$. Further, the morphology and structure of $\mathrm{Ti}_{3} \mathrm{C}_{2}$ and the composite nanomaterial (PEDOT:PSS $/ \mathrm{Ti}_{3} \mathrm{C}_{2} / \mathrm{GQD}$ ) were then analyzed by using SEM as shown in Figure 3B,C. It shows the top view of images of $\mathrm{Ti}_{3} \mathrm{C}_{2}$ display two-dimensional multilayers and restacking in the sheet which in agreement with the previous report $[13,14]$. Subsequently, the nanocomposite shows a more aggregated, rough surface, resembling flakes, probably due to high surface energy between $\mathrm{Ti}_{3} \mathrm{C}_{2}$ and GQD nanoparticles which resulted in agglomeration [27].
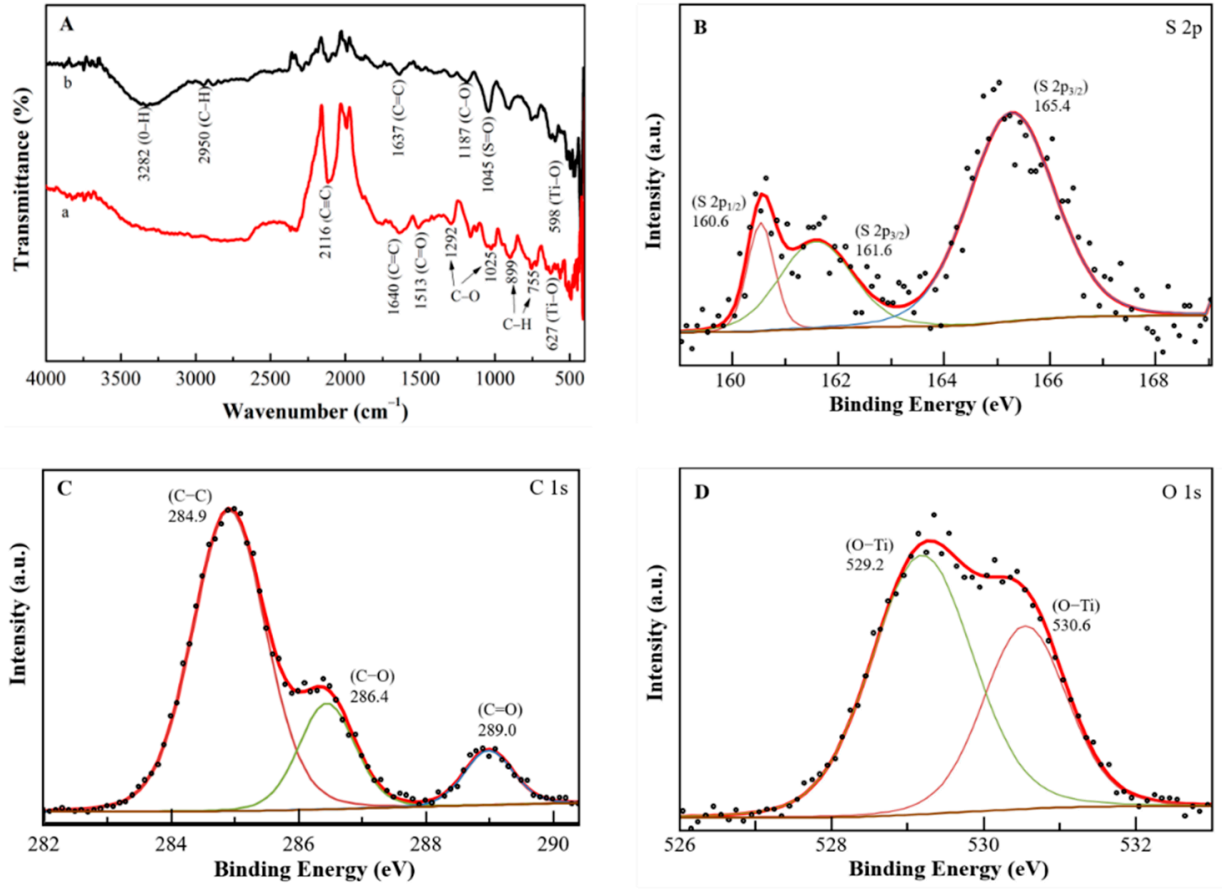

Figure 2. (A) FTIR spectrum of (a) PEDOT:PSS/ $\mathrm{Ti}_{3} \mathrm{C}_{2} / \mathrm{GQD}$ and (b) PEDOT:PSS $/ \mathrm{Ti}_{3} \mathrm{C}_{2} / \mathrm{GQD}$ in presence of GOx immobilization. XPS spectrum and high-resolution XPS spectra of (B) S 2p, (C) C 1s and (D) $\mathrm{O} 1 \mathrm{~s}$ of the PEDOT:PSS $/ \mathrm{Ti}_{3} \mathrm{C}_{2} / \mathrm{GQD}-\mathrm{GOx}$. 


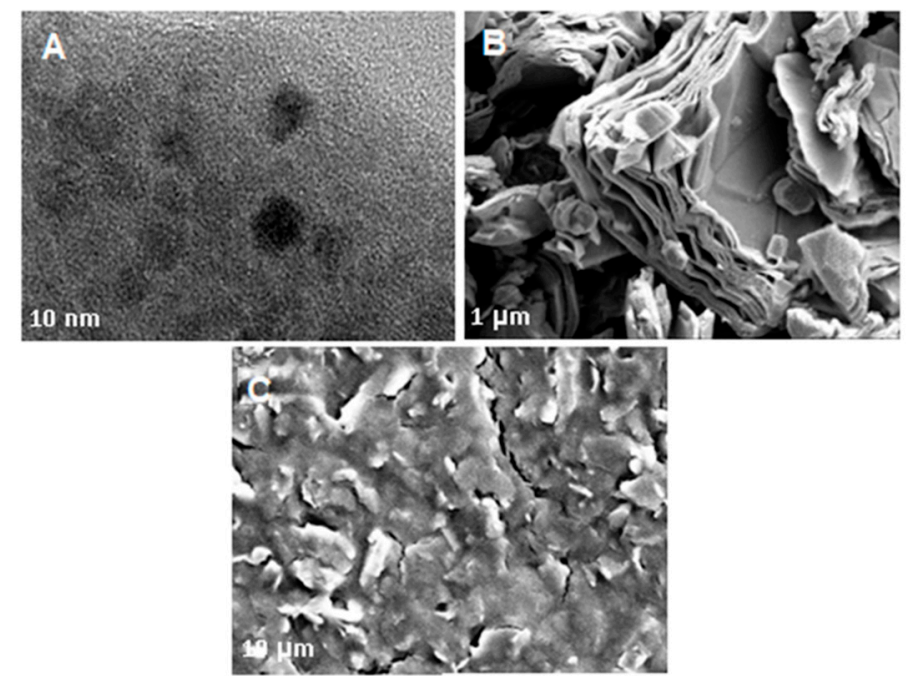

Figure 3. SEM image of (A) HRTEM image of GQD. Scale bar corresponds to $20 \mathrm{~nm}$; (B) mXene, $\mathrm{Ti}_{3} \mathrm{C}_{2}$, and (C) PEDOT:PSS $/ \mathrm{Ti}_{3} \mathrm{C}_{2}$.

\subsection{Electrochemical Characterization}

Figure $4 \mathrm{~A}$ shows the cyclic voltammogram of PEDOT:PSS, PEDOT:PSS $/ \mathrm{Ti}_{3} \mathrm{C}_{2}$, and PEDOT:PSS $/ \mathrm{Ti}_{3} \mathrm{C}_{2} / \mathrm{GQD}$, respectively in the presence of $\mathrm{K}_{3}\left[\mathrm{Fe}(\mathrm{CN})_{6}\right]$ as a redox probe. A pair of well-defined redox peak is observed with a peak to peak separation ( $\Delta \mathrm{Ep})$ of $140 \mathrm{mV}$ for bare SPCE, whereas the $\triangle$ Ep exhibited by the PEDOT:PSS, PEDOT:PSS $/ \mathrm{Ti}_{3} \mathrm{C}_{2}$, and PEDOT:PSS $/ \mathrm{Ti}_{3} \mathrm{C}_{2} / \mathrm{GQD}$ is about 210, 230, and $234 \mathrm{Mv}$ and respectively. When compared to the bare SPCE, the redox peak current demonstrated a significant increase for the PEDOT:PSS $/ \mathrm{Ti}_{3} \mathrm{C}_{2} / \mathrm{GQD}$.
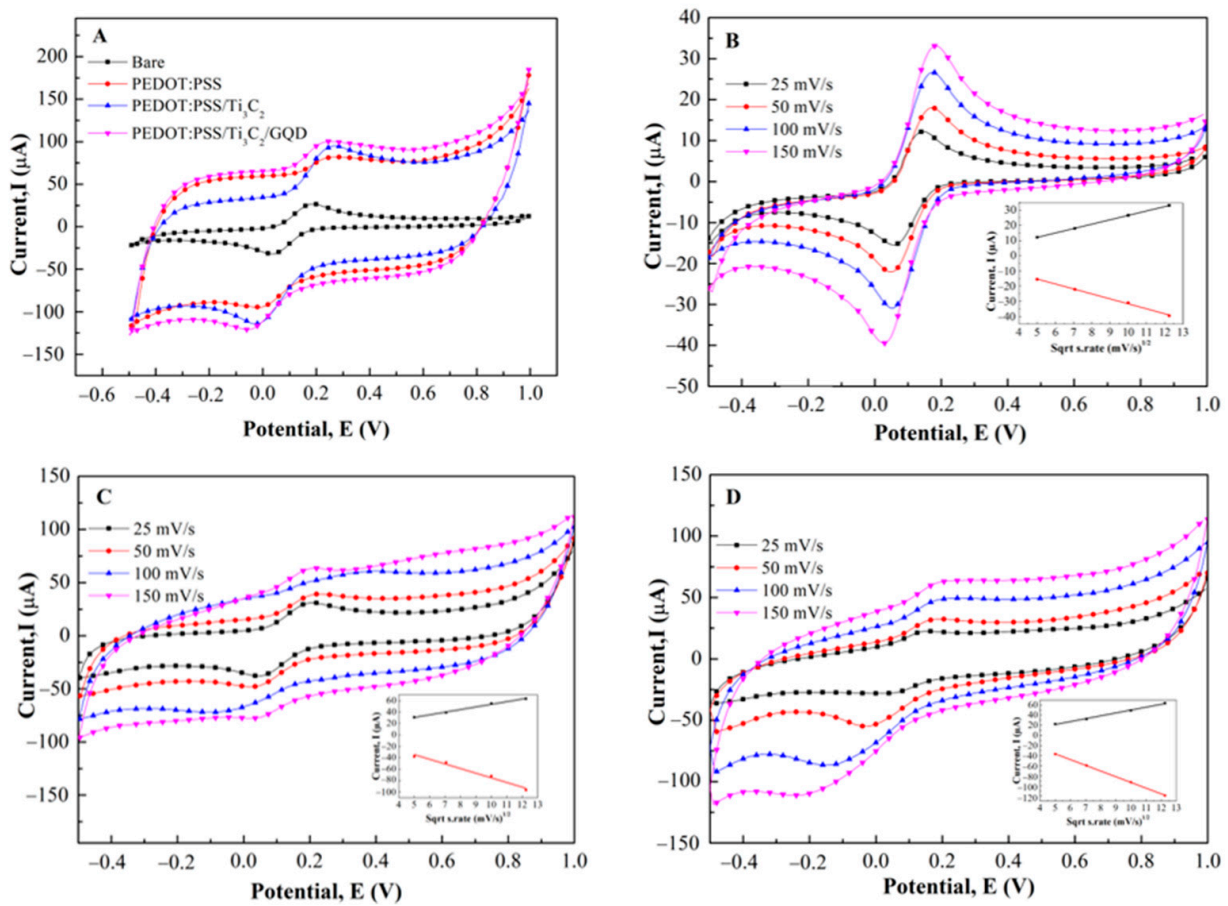

Figure 4. (A) $\mathrm{CV}$ measurements of SPCE/PEDOT:PSS/ $\mathrm{Ti}_{3} \mathrm{C}_{2} / \mathrm{GQD}$ (Pink) compared to SPCE/PEDOT:PSS (Red), PEDOT:PSS/ $\mathrm{Ti}_{3} \mathrm{C}_{2}$ (blue) and bare SPCE (Black) in $0.1 \mathrm{M}$ $\mathrm{K}_{3}\left[\mathrm{Fe}(\mathrm{CN})_{6}\right]$ with ammonium acetate solution at $\mathrm{pH}$. CV measurement of (B) Bare SPCE, (C) SPCE/PEDOT:PSS $/ \mathrm{Ti}_{3} \mathrm{C}_{2}$, and (D) SPCE/PEDOT:PSS/ $\mathrm{Ti}_{3} \mathrm{C}_{2} / \mathrm{GQD}$ at various scan rates 25 , 50,100 and $150 \mathrm{mV} / \mathrm{s}$. Anodic Peak currents as a function of square root scan rate for the determination of the effective working surface area (Inset). 
In addition, the effect of scan rates (from 25 to $150 \mathrm{mVs}^{-1}$ ) on the peak currents at PEDOT:PSS $/ \mathrm{Ti}_{3} \mathrm{C}_{2} / \mathrm{GQD}$ electrode was investigated. As can be seen in Figure $4 \mathrm{~B}-\mathrm{D}$, the plot of the square root scan rate vs. peak current of bare SPCE, PEDOT:PSS $/ \mathrm{Ti}_{3} \mathrm{C}_{2}$, and PEDOT:PSS $/ \mathrm{Ti}_{3} \mathrm{C}_{2} / \mathrm{GQD}$ (inset) exhibited a linear calibration with coefficient regression of $0.9999,0.9895$, and 0.9953 respectively, showed that the process is diffusion-controlled [28]. Moreover, by using the Randles-Sevcik equation, the calculated effective surface area for bare SPCE, PEDOT:PSS $/ \mathrm{Ti}_{3} \mathrm{C}_{2}$, and PEDOT:PSS $/ \mathrm{Ti}_{3} \mathrm{C}_{2} / \mathrm{GQD}$ were $0.013 \mathrm{~cm}^{2}, 0.021$ $\mathrm{cm}^{2}$, and $0.026 \mathrm{~cm}^{2}$, respectively. Compared to bare SPCE, the effective surface area (A) of PEDOT:PSS $/ \mathrm{Ti}_{3} \mathrm{C}_{2}$ was significantly enhanced by about $62 \%$ compared to bare SPCE. This suggested that the increment of the electroactive surface was largely attributed to PEDOT:PSS $/ \mathrm{Ti}_{3} \mathrm{C}_{2}$.

\subsection{Response Characteristics of the PEDOT:PSS/Ti ${ }_{3} \mathrm{C}_{2} / G Q D-G O x$ Electrode toward Glucose}

The CVs of PEDOT:PSS $/ \mathrm{Ti}_{3} \mathrm{C}_{2} / \mathrm{GQD}$ electrode in $0.1 \mathrm{M}$ ammonium acetate solution $(\mathrm{pH}=7.0)$ in the presence and absence of $500 \mu \mathrm{M}$ glucose oxide are recorded in Figure 5. It can be seen that a small oxidation and reduction peak was observed after the addition of GOx, which can be attributed to the consumption of $\mathrm{O}_{2}$ in ammonium acetate solution, which resulted in the redox process [29].

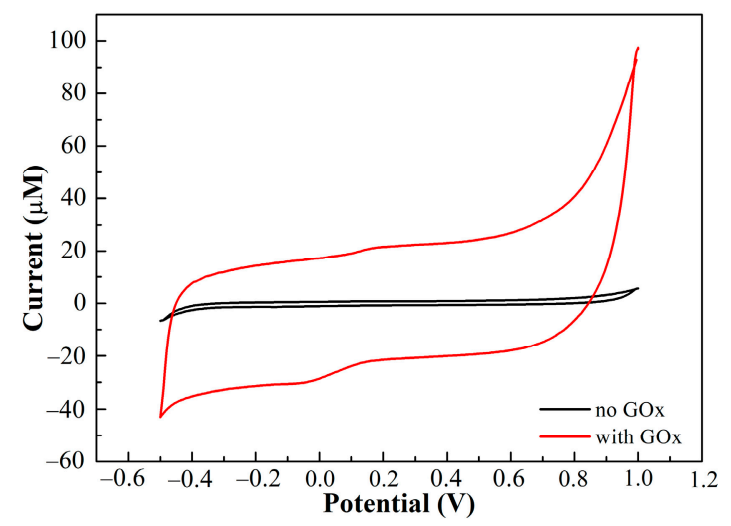

Figure 5. $\mathrm{CV}$ response of the SPCE/PEDOT:PSS $/ \mathrm{Ti}_{3} \mathrm{C}_{2} / \mathrm{GQD}$ in the presence and absence of glucose oxidase with $500 \mu \mathrm{M}$ of glucose in ammonium acetate solution at scan rate of $0.01 \mathrm{~V} / \mathrm{s}$.

\subsection{Optimal $p H$ of PEDOT:PSS/Ti ${ }_{3} C_{2} / G Q D$}

In order to examine the idyllic $\mathrm{pH}$ for glucose detection at PEDOT:PSS $/ \mathrm{Ti}_{3} \mathrm{C}_{2} / \mathrm{GQD}$ SPCE, different $\mathrm{pH}$ buffer solutions $(\mathrm{pH} 4.5-\mathrm{pH}$ 8) have been investigated using DPV and $\mathrm{CV}$, respectively [30]. Figure 6A shows the influence of $\mathrm{pH}$ on the developed biosensor, the results reveal that $\mathrm{pH} 7.0$ has the highest peak oxidation current suggesting the optimum for enzyme activity in this study [30]. In addition, above $\mathrm{pH} 8.0$, the oxidation peak current decreased significantly which might be due to denaturation and a loss in enzyme activity [31]. Therefore, the ammonium acetate solution at $\mathrm{pH} 7.0$ was selected for further investigation of PEDOT:PSS $/ \mathrm{Ti}_{3} \mathrm{C}_{2} / \mathrm{GQD} / \mathrm{GOx}$ SPCE. Moreover, in most cases, the redox behaviors of GOx are often greatly dependent on the solution $\mathrm{pH}$. In this study, a negative shift of both the redox peak potentials of GOx appeared when the $\mathrm{pH}$ value of the solution increased. The formal potential ( $\left.\mathrm{EO}^{\prime}\right)$ showed a good linear function with $\mathrm{pH}$ solution in the range of 4.5-8.0 where the linearity for glucose detection has been confirmed by the peak potential plot in Figure 6B. The acquired slope value was found to be $58.1 \mathrm{mV}$ per $\mathrm{pH}$ unit, following the Nernst equation [32], which confirms the same number of protons and electrons involved in the PEDOT:PSS $/ \mathrm{Ti}_{3} \mathrm{C}_{2} /$ GQD SPCE mechanism [33]. 

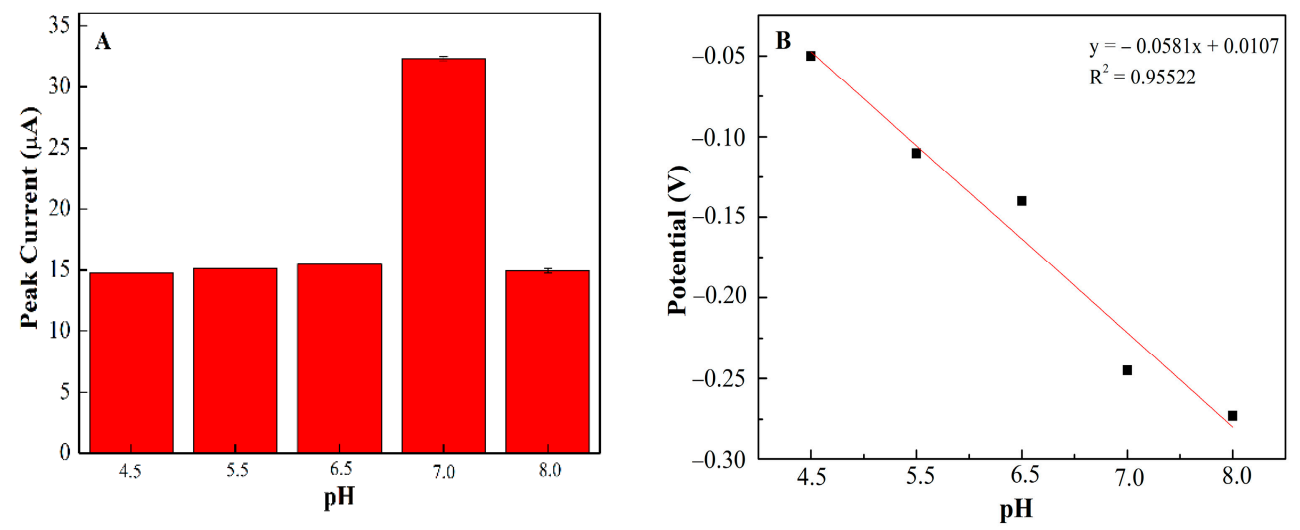

Figure 6. (A) The effect of $\mathrm{pH}$ on the DPV signal of PEDOT:PSS $/ \mathrm{Ti}_{3} \mathrm{C}_{2} / \mathrm{GQD}$ in $0.1 \mathrm{M}$ ammonium acetate solution; (B) The relationship between the potential (V) and $\mathrm{pH}$ of solution.

\subsection{PEDOT:PSS/Ti ${ }_{3} \mathrm{C}_{2} / G Q D / S P C E$ as a Transducer}

Figure 7 depicts the correlation between sensor responses and target concentrations using differential pulse voltammetry and ferrocyanide/ferricyanide redox probe. Using this platform, the limit of detection (LOD) and limit of quantification (LOQ) were calculated using $3 \sigma /$ slope and $10 \sigma /$ slope respectively, where $\sigma$ is the residual standard deviation. As a result, PEDOT:PSS $/ \mathrm{Ti}_{3} \mathrm{C}_{2} / \mathrm{GQD}$ modified SPCE showed an outstanding performance for glucose determination in the broad linear range $0-500 \mu \mathrm{M}\left(\mathrm{R}^{2}=0.9875\right)$ with the limit of detection (LOD) and limit of quantification (LOQ) of $65 \mu \mathrm{M}$ and $217 \mu \mathrm{M}$ (Figure 7A,B) respectively. Meanwhile, the calculated sensitivity exhibited high sensitivity of about $21.64 \mu \mathrm{AmM}^{-1} \mathrm{~cm}^{-2}$, where the values seemed to be within an acceptable range and [34] comparable to the previous study, as shown in Table 1 . The linearity of glucose concentration on modified electrodes (Figure 7B) with regression value is almost 1.0.
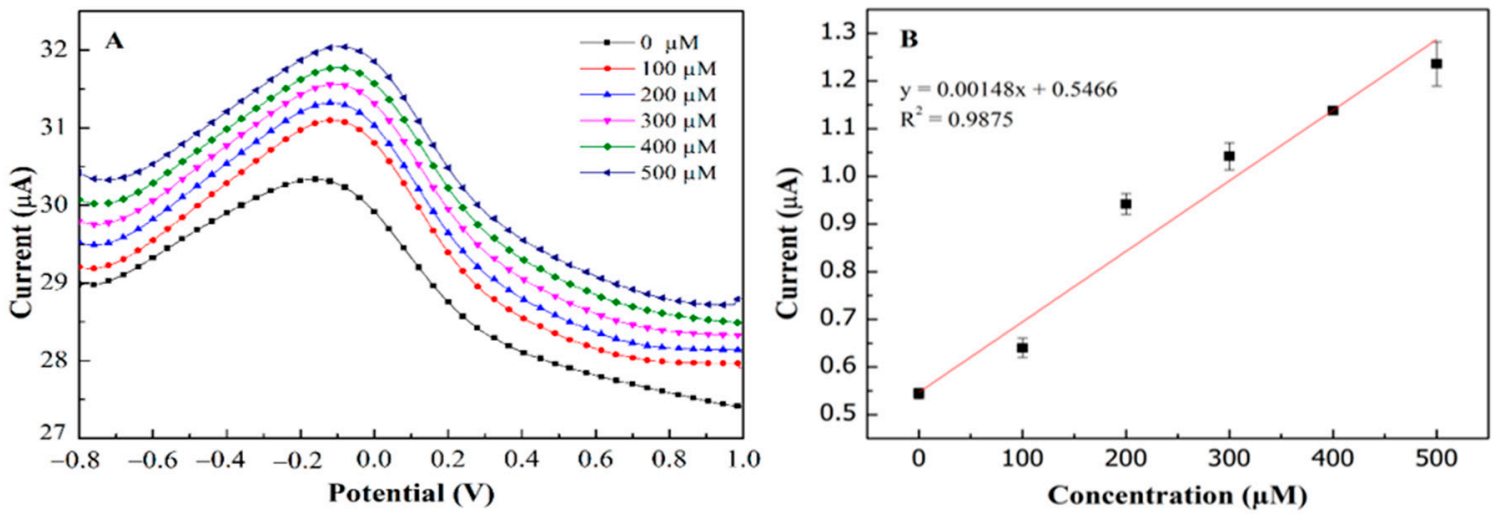

Figure 7. The concentration of glucose detection with linear range $0-500 \mu \mathrm{M}$ at SPCE/PEDOT: PSS/ $\mathrm{Ti}_{3} \mathrm{C}_{2} / \mathrm{GQD}_{-} \mathrm{GOx}$, (A) DPV analysis for $0-500 \mu \mathrm{M}$ of glucose; (B) linearity of glucose concentration vs. current oxidation peak (Ipa). 
Table 1. Summary of glucose detection in an electrochemical system with modification of SPE.

\begin{tabular}{|c|c|c|c|c|}
\hline Modification & Technique & $\begin{array}{l}\text { LOD } \\
(\mu \mathrm{M})\end{array}$ & $\begin{array}{c}\text { Sensitivity } \\
\left(\mu \mathrm{AmM}^{-1} \mathrm{~cm}^{-2}\right)\end{array}$ & References \\
\hline rGO-PEDOT:PSS ${ }^{\text {a }}$ & $\mathrm{CV}$, Amperometric & 86.8 & 57.3 & [35] \\
\hline GOx/AuNP/PANI/rGO/NH ${ }_{2}$-MWCNTs $b$ & Amperometric & 64.0 & 246 & [36] \\
\hline $\mathrm{Pt} / \mathrm{rGO} / \mathrm{P} 3 \mathrm{ABA}^{\mathrm{c}}$ & Chronoamperometric & 44.3 & 22.0 & [37] \\
\hline $\mathrm{Li} / \mathrm{rGO} / \mathrm{APBA}^{\mathrm{d}}$ & $\mathrm{CV}$ & 30.0 & - & [38] \\
\hline $\mathrm{Ni}(\mathrm{OH})_{2} / \mathrm{AuNp}$ & $\mathrm{CV}$ & 40.0 & - & [39] \\
\hline GOx/Pt-graphite & Chronoamperometric & 10.0 & 10.5 & [40] \\
\hline PEDOT:PSS $/ \mathrm{Ti}_{3} \mathrm{C}_{2} /$ GQD-GOx & $\mathrm{CV}, \mathrm{DPV}$ & 65.0 & 21.64 & this work \\
\hline
\end{tabular}

Glucose detection on modified electrode; ${ }^{a}$ reduced graphene oxide (rGO); ${ }^{\mathrm{b}}$ multiwalled carbon nanotubes $(\mathrm{MWCNTs}){ }^{\mathrm{c}}$ poly(3aminobenzoic acid ( $\left.\mathrm{P}_{3} \mathrm{ABA}\right){ }^{\mathrm{d}}$ aminophenylboronic acid (APBA).

\subsection{Stability, Repeatability and Selectivity of the Modified Electrode}

Repeatability studies of the developed sensor were measured using cyclic voltammetry (CV). A concentration of $500 \mu \mathrm{M}$ glucose demonstrates a good current signal with 4 consecutive cycles using the same electrode with a relative standard deviation (RSD) of $2.05 \%$. The steady-state current was still sustained at $90 \%$ of its initial response (Figure 8A). This means that a slight change in the oxidation-reduction peak was observed (Figure S2). The repeatability values are considered acceptable for four replications [41]. The long-term storage stability of PEDOT:PSS/ $\mathrm{Ti}_{3} \mathrm{C}_{2} / \mathrm{GQD}$ with GOx on SPCE was also investigated. After one-month storage at ambient conditions, a slight decrease in the anodic and cathodic peak current [42] was observed (Figure 8A). The anodic and cathodic peak current was still retained above $81 \%$ and $72 \%$ of its initial response after one month (Figure $8 \mathrm{~A}$ ). The result shows that GOx is not leaching on the electrode surface even after 1 month. This suggested that the fabricated biosensors had outstanding storage stability and durability for analyte sensing in the free solution.

The interference effect analysis on glucose determination was performed using DPV under the same experimental conditions (Figure 8B). The interference of glucose with the presence of AA, UA, and creatinine was investigated using $50 \mathrm{M}$, and the effects on the current response of the proposed biosensor are shown in Figure 8B. During the measurement, the oxidation currents of AA and creatinine have been observed, as a result, no significant response was observed for the addition of ascorbic acid $(0.25 \%)$, uric acid $(0.05 \%)$ and creatinine $(0.18 \%)$. These findings indicate that SPCE/PEDOT:PSS $/ \mathrm{Ti}_{3} \mathrm{C}_{2} / \mathrm{GQD} / \mathrm{GOx}$ is highly selective for glucose and had no interference with AA, UA, and creatinine.
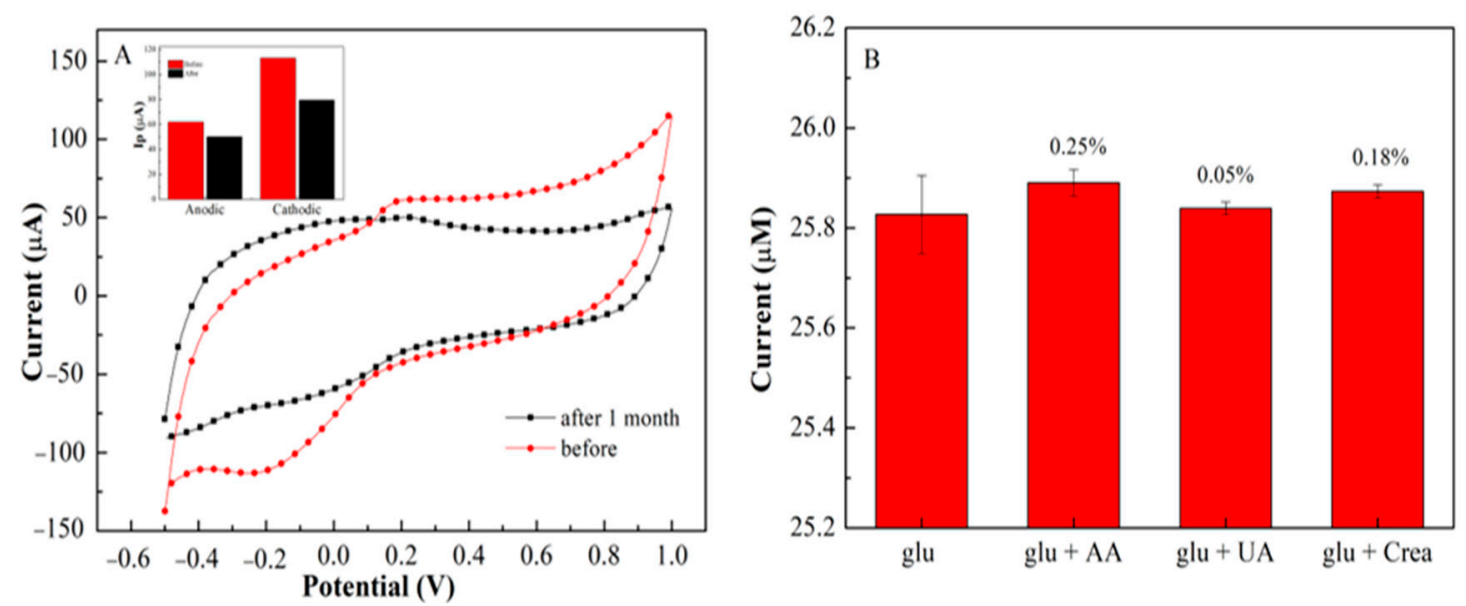

Figure 8. (A) CV stability of 1 -month storage on PEDOT:PSS $/ \mathrm{Ti}_{3} \mathrm{C}_{2} / \mathrm{GQD} / \mathrm{GOx}$ in the prsense $500 \mu \mathrm{M}$ glucose; (B) Interference study of glucose on the PEDOT:PSS $/ \mathrm{Ti}_{3} \mathrm{C}_{2} / \mathrm{GQD}-\mathrm{GOx}$ SPCE. 


\section{Discussion}

In this study, GOx was immobilized only by physical trapping which is governed by a noncovalent interaction strategy, GOx immobilization with natural bonding like hydrophobic, hydrogen bonds, and pi-stacking on the modified electrode is expected. Thus, FTIR characterization has shown appropriated peaks have appeared for both spectra (Figure 2A,B). This peak was responsible for helps GOx immobilization on PEDOT:PSS/ $\mathrm{Ti}_{3} \mathrm{C}_{2} / \mathrm{GQD}$. For XPS characterization, the results obtained indicated that the PEDOT:PSS/ $\mathrm{Ti}_{3} \mathrm{C}_{2} / \mathrm{GQD}$ were composed of three elements of $\mathrm{C}, \mathrm{S}$, and $\mathrm{O}$ with multiple oxygencontaining groups and titanium groups on the surface of the PEDOT:PSS $/ \mathrm{Ti}_{3} \mathrm{C}_{2} / \mathrm{GQD}$. Due to the strictly superficial nature of the XPS analysis, there is clear evidence of the presence of GOx protein-covered elements [26].

As far as morphologies are concerned, GQD and $\mathrm{Ti}_{3} \mathrm{C}_{2}$ showed the expected images where the findings were satisfied by previous studies $[13,14]$. Meanwhile, the images for composite nanomaterial show a more aggregated rough surface, which might due to the high surface energy between $\mathrm{Ti}_{3} \mathrm{C}_{2}$ and GQD nanoparticles that resulted in the agglomeration of PEDOT:PSS $/ \mathrm{Ti}_{3} \mathrm{C}_{2} / \mathrm{GQD}$.

Subsequently, the result from Figure $4 \mathrm{~A}$ shows the improved electrochemical behavior can be attributed to the excellent electrical conductivity of the $\mathrm{Ti}_{3} \mathrm{C}_{2}$ and GQD present on the electrode surface could accelerate the electron transfer rate at the electrode/electrolyte interface [43-45]. In regard to the presence of $\mathrm{Ti}_{3} \mathrm{C}_{2}$ and GQD, they provide additional active surface area, thus resulting in better exposure of electroactive sites compared to PEDOT:PSS alone [23,46]. Interestingly, the electroactive surface area of modified SPCE modified PEDOT:PSS $/ \mathrm{Ti}_{3} \mathrm{C}_{2} / \mathrm{GQD}$ exhibited an increase about two-fold, indicating good synergistic effects between GQD, $\mathrm{Ti}_{3} \mathrm{C}_{2}$, and PEDOT:PSS.

The electrocatalytic activity of fabricated biosensor in this study can briefly be described as below, where FAD is reduced to $\mathrm{FADH}_{2}$ during glucose oxidation by accepting electrons from the glucose activity mechanism of an enzyme on the electrode:

$$
\begin{gathered}
\text { Glucose }+ \text { GOx }(\mathrm{FAD}) \rightarrow \text { Gluconolactone }+\mathrm{GOx}\left(\mathrm{FADH}_{2}\right) \\
\text { GOx }\left(\mathrm{FADH}_{2}\right)+\mathrm{O}_{2} \rightarrow \mathrm{H}_{2} \mathrm{O}_{2}+\mathrm{GOx}(\mathrm{FAD}) \\
\mathrm{H}_{2} \mathrm{O}_{2} \rightarrow \mathrm{O}_{2}+2 \mathrm{H}++2 \mathrm{e}^{-}
\end{gathered}
$$

\section{Conclusions}

A novel nanomaterial for the development of an electrochemical sensor to determine glucose based on PEDOT:PSS $/ \mathrm{Ti}_{3} \mathrm{C}_{2} / \mathrm{GQD}$ has been proposed in this study. The GOx enzyme was immobilized on PEDOT:PSS $/ \mathrm{Ti}_{3} \mathrm{C}_{2} / \mathrm{GQD}$ modified SPCE by a simple electrochemical process. From CV measurement, the direct electrochemistry of GOx on PEDOT:PSS $/ \mathrm{Ti}_{3} \mathrm{C}_{2}$ /GQD electrode is observed. PEDOT:PSS/ $\mathrm{Ti}_{3} \mathrm{C}_{2} /$ GQD modified electrodes are proven to offer the efficient detection of glucose with a comparable limitation (LOD) of $65 \mu \mathrm{M}$ and LOQ of $217 \mu \mathrm{M}$, as well as high sensitivity of $21.64 \mu \mathrm{AmM}^{-1} \mathrm{~cm}^{-2}$. Thus, the PEDOT:PSS $/ \mathrm{Ti}_{3} \mathrm{C}_{2}$ /GQD-GOx shows remarkable improvement in terms of stability and repeatability. The results for this study demonstrate simple guidelines to improve SPCE based on nanocomposite PEDOT:PSS $/ \mathrm{Ti}_{3} \mathrm{C}_{2} / \mathrm{GQD}$ for the efficient detection of glucose. The excellent performance of the prepared composite film can also be investigated for the immobilization of other redox enzymes or proteins.

Supplementary Materials: The following are available online at https:/ /www.mdpi.com/article/10 $.3390 /$ bios11080267/s1, Figure S1: The general survey of the XPS spectrum of the PEDOT:PSS $/ \mathrm{Ti}_{3} \mathrm{C}_{2} /$ GQD with three strong binding energy peaks of $S 2 p, C$ ss, and O 1s. Figure S2: Repeatability of the modified electrode in four cycles after 1-month storage, Figure S3: CV stability of 1-month storage on PEDOT:PSS $/ \mathrm{Ti}_{3} \mathrm{C}_{2} / \mathrm{GQD}$ with GOx.

Author Contributions: Designed the experiments; M.F.M.R.W. and S.N.A.N., Characterization; S.N.A.N., M.A.S.M.H., and M.F.M.R.W., Analyzed the data; S.N.A.N., and O.P.C., Writing, review, 
and editing: S.N.A.N., M.H.M.Z., J.A., and M.F.M.R.W. All the authors contributed in the preparation and writing of the manuscript. All authors have read and agreed to the published version of the manuscript.

Funding: This research was funded by GGPM-2018-015 and AKU254: HiCoE (Fasa 11) 'MEMS for Biomedical Devices (artificial kidney)' from the Ministry of Education Malaysia for this work.

Institutional Review Board Statement: Not applicable.

Informed Consent Statement: Not applicable.

Data Availability Statement: Data is contained within the article or Supplementary Materials.

Conflicts of Interest: The authors declare no conflict of interest.

\section{References}

1. Wu, L.N.; Zhong, J.P.; Waqas, M.; Jiang, Z.; Fan, Y.J.; Sun, Y.; Li, J.; Chen, W. Controllable synthesis of six corner star-like Cu2O/PEDOT-MWCNT composites and their performance toward electrochemical glucose sensing. Electrochim. Acta 2019, 318, 837-846. [CrossRef]

2. Devi, K.S.S.; Sasya, M.; Krishnan, U.M. Emerging vistas on electrochemical detection of diabetic retinopathy biomarkers. TrAC Trends Anal. Chem. 2020, 125, 115838. [CrossRef]

3. Yamanaka, K.; Vestergaard, M.C.; Tamiya, E. Printable electrochemical biosensors: A focus on screen-printed electrodes and their application. Sensors 2016, 16, 1761. [CrossRef] [PubMed]

4. Moreira, F.T.C.; Ferreira, M.J.M.S.; Puga, J.R.T.; Sales, M.G.F. Screen-printed electrode produced by printed-circuit board technology. Application to cancer biomarker detection by means of plastic antibody as sensing material. Sens. Actuators B Chem. 2016, 223, 927-935. [CrossRef] [PubMed]

5. Termehyousefi, A.; Tanaka, H.; Bagheri, S. Enhancement of glucose oxide electron-transfer mechanism in glucose biosensor via optimum physical chemistry of functionalized carbon nanotubes. Rev. Chem. Eng. 2017, 33, 201-215. [CrossRef]

6. Taleat, Z.; Khoshroo, A.; Mazloum-Ardakani, M. Screen-printed electrodes for biosensing: A review (2008-2013). Microchim. Acta 2014, 181, 865-891. [CrossRef]

7. Tukimin, N.; Abdullah, J.; Sulaiman, Y. Development of a PrGo-modified electrode for uric acid determination in the presence of ascorbic acid by an electrochemical technique. Sensors 2017, 17, 1539. [CrossRef]

8. Dechtrirat, D.; Sookcharoenpinyo, B.; Prajongtat, P.; Sriprachuabwong, C.; Sanguankiat, A.; Tuantranont, A.; Hannongbua, S. An electrochemical MIP sensor for selective detection of salbutamol based on a graphene/PEDOT:PSS modified screen printed carbon electrode. RSC Adv. 2018, 8, 206-212. [CrossRef]

9. Wang, J.Y.; Chen, L.C.; Ho, K.C. Synthesis of redox polymer nanobeads and nanocomposites for glucose biosensors. ACS Appl. Mater. Interfaces 2013, 5, 7852-7861. [CrossRef]

10. Wen, Y.; Xu, J. Scientific Importance of Water-Processable PEDOT-PSS and Preparation, Challenge and New Application in Sensors of Its Film Electrode: A Review. J. Polym. Sci. Part A Polym. Chem. 2017, 55, 1121-1150. [CrossRef]

11. Shen, X.; Ju, F.; Li, G.; Ma, L. Smartphone-based electrochemical potentiostat detection system using pedot: Pss/chitosan/graphene modified screen-printed electrodes for dopamine detection. Sensors 2020, 20, 2781. [CrossRef]

12. Kumar, V.; Hebbar, S.; Kalam, R.; Panwar, S.; Prasad, S.; Srikanta, S.S.; Krishnaswamy, P.R.; Bhat, N. Creatinine-iron complex and its use in electrochemical measurement of urine creatinine. IEEE Sens. J. 2018, 18, 830-836. [CrossRef]

13. Yu, X.; Wang, T.; Yin, W.; Zhang, Y. Ti3C2 MXene nanoparticles modified metal oxide composites for enhanced photoelectrochemical water splitting. Int. J. Hydrogen Energy 2019, 44, 2704-2710. [CrossRef]

14. Guo, Y.; Zhou, X.; Wang, D.; Xu, X.; Xu, Q. Nanomechanical Properties of $\mathrm{Ti}_{3} \mathrm{C}_{2}$ Mxene. Langmuir 2019, 35, 14481-14485. [CrossRef]

15. Kalambate, P.K.; Gadhari, N.S.; Li, X.; Rao, Z.; Navale, S.T.; Shen, Y.; Patil, V.R.; Huang, Y. Recent advances in MXene-based electrochemical sensors and biosensors. TrAC Trends Anal. Chem. 2019, 120, 115643. [CrossRef]

16. Wang, D.; Liang, Y.; Su, Y.; Shang, Q.; Zhang, C. Sensitivity enhancement of cloth-based closed bipolar electrochemiluminescence glucose sensor via electrode decoration with chitosan/multi-walled carbon nanotubes/graphene quantum dots-gold nanoparticles. Biosens. Bioelectron. 2019, 130, 55-64. [CrossRef]

17. Kalita, H.; Palaparthy, V.S.; Baghini, M.S.; Aslam, M. Electrochemical synthesis of graphene quantum dots from graphene oxide at room temperature and its soil moisture sensing properties. Carbon 2020, 165, 9-17. [CrossRef]

18. Hu, T.; Zhang, L.; Wen, W.; Zhang, X.; Wang, S. Enzyme catalytic amplification of miRNA-155 detection with graphene quantum dot-based electrochemical biosensor. Biosens. Bioelectron. 2016, 77, 451-456. [CrossRef] [PubMed]

19. Lakshmi, D.; Whitcombe, M.J.; Davis, F.; Sharma, P.S.; Prasad, B.B. Electrochemical Detection of Uric Acid in Mixed and Clinical Samples: A Review. Electroanalysis 2011, 23, 305-320. [CrossRef]

20. Baig, N.; Sajid, M.; Saleh, T.A. Recent trends in nanomaterial-modified electrodes for electroanalytical applications. TrAC Trends Anal. Chem. 2019, 111, 47-61. [CrossRef] 
21. Yukird, J.; Kongsittikul, P.; Qin, J.; Chailapakul, O.; Rodthongkum, N. ZnO@graphene nanocomposite modified electrode for sensitive and simultaneous detection of Cd (II) and $\mathrm{Pb}$ (II). Synth. Met. 2018, 245, 251-259. [CrossRef]

22. Renedo, O.D.; Alonso-Lomillo, M.A.; Martínez, M.J.A. Recent developments in the field of screen-printed electrodes and their related applications. Talanta 2007, 73, 202-219. [CrossRef] [PubMed]

23. Rakhi, R.B.; Nayuk, P.; Xia, C.; Alshareef, H.N. Novel amperometric glucose biosensor based on MXene nanocomposite. Sci. Rep. 2016, 6, 1-10. [CrossRef] [PubMed]

24. Ferrari, A.G.M.; Foster, C.W.; Kelly, P.J.; Brownson, D.A.C.; Banks, C.E. Determination of the electrochemical area of screen-printed electrochemical sensing platforms. Biosensors 2018, 8, 53. [CrossRef]

25. Kumar, S.; Lei, Y.; Alshareef, N.H.; Quevedo-Lopez, M.A.; Salama, K.N. Biofunctionalized two-dimensional Ti3C2 MXenes for ultrasensitive detection of cancer biomarker. Biosens. Bioelectron. 2018, 121, 243-249. [CrossRef]

26. Aleeva, Y.; Maira, G.; Scopelliti, M.; Vinciguerra, V.; Scandurra, G.; Cannata, G.; Giusi, G.; Ciofi, C.; Figa, V.; Occhipinti, L.G.; et al. Amperometric Biosensor and Front-End Electronics for Remote Glucose Monitoring by Crosslinked PEDOT-Glucose Oxidase. IEEE Sens. J. 2018, 18, 4869-4878. [CrossRef]

27. Xi, J.; Xie, C.; Zhang, Y.; Wang, L.; Xiao, J.; Duan, X.; Ren, J.; Xiao, F.; Wang, S. Pd Nanoparticles Decorated N-Doped Graphene Quantum Dots@N-Doped Carbon Hollow Nanospheres with High Electrochemical Sensing Performance in Cancer Detection. ACS Appl. Mater. Interfaces 2016, 8, 22563-22573. [CrossRef] [PubMed]

28. Trindade, E.K.G.; Silva, B.V.M.; Dutra, R.F. A probeless and label-free electrochemical immunosensor for cystatin C detection based on ferrocene functionalized-graphene platform. Biosens. Bioelectron. 2019, 138, 111311. [CrossRef] [PubMed]

29. Shen, X.; Xia, X.; Du, Y.; Ye, W.; Wang, C. Amperometric Glucose Biosensor Based on AuPd Modified Reduced Graphene Oxide/Polyimide Film with Glucose Oxidase. J. Electrochem. Soc. 2017, 164, 2781. [CrossRef]

30. Espro, C.; Marini, S.; Giusi, D.; Ampelli, C.; Neri, G. Non-enzymatic screen printed sensor based on Cu2O nanocubes for glucose determination in bio-fermentation processes. J. Electroanal. Chem. 2020, 873, 114354. [CrossRef]

31. Tiwari, J.N.; Vij, V.; Kemp, K.C.; Kim, K.S. Engineered carbon-nanomaterial-based electrochemical sensors for biomolecules. ACS Nano 2016, 10, 46-80. [CrossRef] [PubMed]

32. Walczak, M.M.; Dryer, D.A.; Jacobson, D.D.; Foss, M.G.; Flynn, N.T. Education pH-dependent redox couple: Illustrating the Nernst equation using cyclic voltammetry. J. Chem. Educ. 1997, 74, 1195-1197. [CrossRef]

33. Kogularasu, S.; Akilarasan, M.; Chen, S.M.; Chen, T.W.; Lou, B.S. Urea-based morphological engineering of ZnO; for the biosensing enhancement towards dopamine and uric acid in food and biological samples. Mater. Chem. Phys. 2019, $227,5-11$. [CrossRef]

34. Bollella, P.; Gorton, L.; Ludwig, R.; Antiochia, R. A third generation glucose biosensor based on cellobiose dehydrogenase immobilized on a glassy carbon electrode decorated with electrodeposited gold nanoparticles: Characterization and application in human saliva. Sensors 2017, 17, 1912. [CrossRef] [PubMed]

35. Abd-Wahab, F.; Guthoos, H.F.A.; Wan Salim, W.W.A. Solid-state rGO-PEDOT:PSS transducing material for cost-effective enzymatic sensing. Biosensors 2019, 9, 36. [CrossRef]

36. Maity, D.; Minitha, C.R.; Rajendra, R.K. Glucose oxidase immobilized amine terminated multiwall carbon nanotubes/reduced graphene oxide/polyaniline/gold nanoparticles modified screen-printed carbon electrode for highly sensitive amperometric glucose detection. Mater. Sci. Eng. C 2019, 105, 110075. [CrossRef]

37. Phetsang, S.; Jakmunee, J.; Mungkornasawakul, P.; Laocharoensuk, R.; Ounnunkad, K. Sensitive amperometric biosensors for detection of glucose and cholesterol using a platinum/reduced graphene oxide/poly(3-aminobenzoic acid) film-modified screen-printed carbon electrode. Bioelectrochemistry 2019, 127, 125-135. [CrossRef] [PubMed]

38. Li, M.; Li, D.W.; Xiu, G.; Long, Y.T. Applications of screen-printed electrodes in current environmental analysis. Curr. Opin. Electrochem. 2017, 3, 137-143. [CrossRef]

39. Rinaldi, A.L.; Rodríguez-Castellón, E.; Sobral, S.; Carballo, R. Application of a nickel hydroxide gold nanoparticles screen-printed electrode for impedimetric sensing of glucose in artificial saliva. J. Electroanal. Chem. 2019, 832, 209-216. [CrossRef]

40. Abellán-Llobregat, A.; Jeerapan, I.; Bandodkar, A.; Vidal, L.; Canals, A.; Wang, J.; Morallón, E. A stretchable and screen-printed electrochemical sensor for glucose determination in human perspiration. Biosens. Bioelectron. 2017, 91, 885-891. [CrossRef]

41. Wisitsoraat, A.; Pakapongpan, S.; Sriprachuabwong, C.; Phokharatkul, D.; Sritongkham, P.; Lomas, T.; Tuantranont, A. GraphenePEDOT:PSS on screen printed carbon electrode for enzymatic biosensing. J. Electroanal. Chem. 2013, 704, 208-213. [CrossRef]

42. Bilgi, M.; Ayranci, E. Biosensor application of screen-printed carbon electrodes modified with nanomaterials and a conducting polymer: Ethanol biosensors based on alcohol dehydrogenase. Sens. Actuators B Chem. 2016, 237, 849-855. [CrossRef]

43. Chaiyo, S.; Mehmeti, E.; Siangproh, W.; Hoang, T.L.; Nguyen, H.P.; Chailapakul, O.; Kalcher, K. Non-enzymatic electrochemical detection of glucose with a disposable paper-based sensor using a cobalt phthalocyanine-ionic liquid-graphene composite. Biosens. Bioelectron. 2018, 102, 113-120. [CrossRef]

44. Słoniewska, A.; Kasztelan, M.; Berbeć, S.; Pałys, B. Influence of buffer solution on structure and electrochemical properties of poly(3,4-ethylenedioxythiophene)/poly(styrenesulfonate) hydrogels. Synth. Met. 2020, 263, 116363. [CrossRef]

45. Soomro, R.A.; Jawaid, S.; Zhu, Q.; Abbas, Z.; Xu, B. A mini-review on MXenes as versatile substrate for advanced sensors. Chinese Chem. Lett. 2020, 31, 922-930. [CrossRef]

46. Campuzano, S.; Yáñez-Sedeño, P.; Pingarrón, J.M. Carbon dots and graphene quantum dots in electrochemical biosensing. Nanomaterials 2019, 9, 634. [CrossRef] 